O30 (continued)

children using qualitative field observations and the socioecological model.

Study Design, Setting, Participants: A convenience sample of families $(n=7)$ with a child $2-5$ years of age from Guadalajara, Mexico, participated in one full day of observation inside the family home. Data collected included: anthropometric measurements; observations of the home environment; interviews to capture primary caregiver's nutrition, child feeding and physical activity (PA) practices; and photo observations of food purchasing, market style/condition, and the neighborhood environment related to childhood obesity.

Outcome Measures and Analysis: Descriptive data were tabulated. Content analysis of field notes were used to identify themes from observations using the socioecological model as a theoretical framework to identify factors related to an obesogenic environment.

Results: The observed children ( $n=5$ male, $n=2$ female) had an average BMI of $15.6 \pm 1.6$. Caregivers (female; 2270 years) had an average BMI of $32.8 \pm 5.4$. Family socioeconomic status (SES) varied (range $<\$ 112 \mathrm{USD} / \mathrm{mo}$ to $>\$ 766 \mathrm{USD} / \mathrm{mo}$ ). Obesogenic factors identified in the microsystems included: parenting styles; availability of childcare; and the primary caregiver's knowledge of nutrition and PA, i.e. food preparation knowledge and skills, and beliefs about PA. Obesogenic factors identified in the macrosystem included: SES; food availability, i.e. limited access to nutrient dense foods; neighborhood safety, i.e. limited access to safe places for outdoor PA; and accessibility to markets with nutrient dense foods.

Conclusions and Implications: Factors were identified that may contribute to childhood obesity; however, further research is needed to confirm prevalence of these factors across populations in Mexico.

Funding: None

\section{Eat Smart, Move More in Schools: A Comprehensive Program to Improve the School Food Environment Outside of the NSLP Developed Through a Multi-State Collaboration}

Sarah Misyak, PhD, Virginia Tech; Alisha Farris, $P h D, R D N$, alisha@vt.edu, Auburn University, Auburn, AL 36849; Georgianna Mann, PhD, University of Mississippi;

Elena Serrano, $P h D$, Virginia Tech

Objective: As National School Lunch Program (NSLP) standards have been implemented, some research suggests fruit and vegetable consumption has increased in schools. However, foods brought from home and other foods served outside of the NSLP, such as packed lunches and snacks, are of poorer nutritional quality. The objective of Eat Smart, Move More in Schools is to improve the nutritional quality of foods consumed in schools through comprehensive programming addressing multiple aspects of the school food environment.

Target Audience: Elementary-aged children.
Theory, Prior Research, Rationale: The Eat Smart, Move More in Schools program uses the social ecological model as a conceptual framework.

Description: Eat Smart, Move More in Schools is a program offered in 2017 combining direct education offered through SNAP-Ed, support to parents through the use of a packed lunch cookbook, support to schools for strengthening wellness policies and the nutritional quality of schools snacks, and a social marketing campaign coordinated by SNAP-Ed through Cooperative Extension. Evaluation: The SNAP-Ed Evaluation Framework was used to develop an evaluation plan. Indicators include those addressing individual behavior change as measured through teacher evaluation surveys, environmental changes measured through the potential change in school lunches through the use of the packed lunch cookbook, policy changes measured through school wellness policies, and change agent/school wellness champion perception of the changes in sectors of influence.

Conclusions and Implications: Eat Smart, Move More in Schools in an example of a comprehensive intervention developed through a multi-state collaboration.

Funding: Supplemental Nutrition Assistance Program Education

\section{Which School Districts Are Using the Community Eligibility Provision to Offer Free School Meals to All Their Students?}

Stephanie Rogus, $M A, R D$, New York University and Economic Research Service, USDA; Katherine Ralston, $P h D$; Joanne F. Guthrie,PhD, MPH, RD, jguthrie@ers.usda.gov, New York University, 1400 Independence Avenue, SW, Mailstop 1800, Washington, DC 20520-1800

Objective: The Community Eligibility Provision (CEP) of the Healthy, Hunger-free Kids Act of 2010 allows schools and districts with large numbers of low-income students to offer all students free school meals using administrative data on the percentage of students receiving SNAP (formerly food stamps) and other means-tested assistance (the Identified Student Percentage or ISP). The study objective is to identify school district characteristics associated with CEP adoption.

Study Design, Setting, Participants, Intervention: Administrative data on CEP eligibility and participation from USDA's Food and Nutrition Service and state education agencies are matched with National Center for Education Statistics data to estimate a model of school district participation in CEP.

Outcome Measures and Analysis: Our outcome measure is school district participation in CEP. We test associations with district size, rural/urban designation, and ISP level using cross-tabulations and logistic regression.

Results: Small school districts, urban districts, and those with ISPs above $60 \%$ are most likely to adopt CEP. Controlling for region, ISP most strongly predicts participation. Districts with any school at an ISP of $60-70 \%$ are 6 times more likely to participate in CEP compared to other districts, whereas districts where the highest school-level ISP 


\section{O32 (continued)}

in the district is $90-100 \%$ are 10 times more likely to participate than those without any schools with ISPs between $90 \%$ and $100 \%$.

Conclusions and Implications: Understanding district characteristics associated with CEP participation informs discussion of school meal program effectiveness as part of upcoming Federal reauthorization of child nutrition programs. It also helps target strategies to encourage CEP participation by eligible districts that may benefit from CEP.

Funding: USDA

\section{Formative Research: Key Drivers Affecting Diet Quality of Home-Packed Lunch in Parents of Young School Children}

Perrine Nadaud, MS, pnadaud@umd.edu, University of Maryland, College Park, 0112 Skinner Building, College Park, MD 20742; Hee-Jung Song, PhD, University of Maryland

Objective: Although existing studies suggest that homepacked lunches (HPL) fall short of dietary guidelines and need nutritional improvement, there have been relatively little studies focusing on dietary quality of HPL. This study examined key determinants affecting parents' lunch packing behaviors and their associations with their child's diet quality.

Study Design, Setting, Participants: For this formative research, parents of kindergartener and first grade children who regularly consume home-packed lunches $(n=56)$ were recruited from eight public schools in Maryland.

Outcome Measures and Analysis: Using a semi-structured survey, parents' decisional balance to prepare HPL, their food packing behavior and key psychosocial variables affecting their child's diet quality were collected. Parents reported their child's food intake using the Automated Self-Administered 24-hour Recall (ASA24-2016) and the diet quality of HPL was measured using the Healthy Eating Index-2010 (HEI). Multiple linear regression models adjusted for confounders were used to determine these associations.

Results: The mean HEI score was 61. Parents' self-efficacy for helping their child have healthy eating behavior was positively associated with their child's diet quality ( $\beta=0.67, \mathrm{p}=0.02$ ) while spouse unemployment was negatively associated with their child's diet quality ( $\beta=-45.2 \mathrm{p}<0.0001)$. Reportedly, the main reasons for not buying school meals were that parents wanted to choose what their child ate $(53.7 \%)$, and perceived that the school meals are unhealthy (46.3\%) and their child will not eat them (40.7\%).

Conclusions and Implications: Future interventions are required to help parents and children bring HPL in line with recommend dietary guidelines and should incorporate parents' key psychosocial variables including selfefficacy to enact healthy lifestyles in their children.

Funding: None

\section{Parent Perceptions of School Breakfast in Three States with Low Participation}

Natoshia M. Askelson, PhD, MPH, natoshia-askelson@ uiowa.edu, University of Iowa, 145 North Riverside Drive, Iowa City, IA 52242; Lori Andersen Spruance, PhD, Brigham Young University; Zainab Rida, PhD, RD, LMNT, Nebraska Department of Education

Objective: To determine parents' perceptions of school breakfast in the lowest school breakfast participation states, Utah, Nebraska and Iowa.

Study Design, Setting, Participants: Parents of school-aged children were recruited via email to participate in an online survey: Utah $(n=489$ Nebraska $(n=756)$, and Iowa $(n=8,982)$.

Outcome Measures and Analysis: The survey asked parents about their knowledge of the program, attitudes, benefits to their family, child's participation, and perceptions of school breakfast.

Results: When asked about benefits school breakfast might have for their families, parents reported breakfast would be convenient (Utah 42.94\%, Nebraska 36.00\%, and Iowa 40.7\%), make their morning less stressful (Utah 27.61\%, Nebraska 18.50\%, and Iowa 21.0\%), and their child would not be hungry in the morning (Utah 20.45\%, Nebraska 15.9\%, and Iowa 17.2\%). Parents saw school breakfast as an opportunity for their child to have a nutritious meal (Utah 20.25\%, Nebraska 11.4\%, and Iowa $15.5 \%)$. Many parents saw no benefit for their families (Utah 33.54\%, Nebraska 42.50\%, and Iowa 21.8\%). Parents believed school breakfast was for parents who did not have enough money (Utah 70.35\%, Nebraska 55.4\%, Iowa $44.20 \%$ ) and for parents who did not care enough (Utah 43.35\%, Nebraska 39.8\%, 29.50\%).

Conclusions and Implications: The results from this study suggest more efforts need to be made to increase positive perceptions of school breakfast among parents. These strategies may include emphasizing the benefits of the program and decreasing stigma around the program through efforts such as social marketing campaigns and including breakfast in school wellness policies.

Funding: None

\section{WITHDRAWN}

\section{School Cafeteria Noise is Associated with Fruit and Vegetable (FV) Consumption at Lunch Among Elementary School Students}

Matthew M. Graziose, MS, mmg2198@tc.columbia.edu, Columbia University, 525 West 125th Street, Box 137, New York, NY 10027; Pamela Koch, EdD, RD, Columbia University; Randi Wolf, PhD; Heewon Lee Gray, PhD, RD; Isobel Contento, PhD, RD 